\title{
Minor Structural Alterations of the Vocal Fold Cover: Vocal Quality before and after Treatment
}

\author{
Tatiany Cíntia da Silva Brito ${ }^{1}$ Jullyane Florencio Pacheco da Silva ${ }^{1}$ Bruno Teixeira Moraes ${ }^{2,3}$ \\ Mirella Bezerra Rodrigues Vilela ${ }^{1}$ Coeli Regina Ximenes ${ }^{1}$ Daniela de Vasconcelos ${ }^{3}$ \\ Nathália Suellen Valeriano Cardoso ${ }^{4}$ Adriana de Oliveira Camargo Gomes ${ }^{1,4}$
}

${ }^{1}$ Department of Speech Therapy, Universidade Federal de Pernambuco, Recife, PE, Brazil

2 Department of Surgery, Universidade Federal de Pernambuco, Recife, PE, Brazil

3 Otorhinolaryngology Outpatient Clinic, Clinical Hospital of Pernambuco, Recife, PE, Brazil

${ }^{4}$ Graduate Program in Human Communication Health, Health Sciences Center, Universidade Federal de Pernambuco, Recife, PE, Brazil

Int Arch Otorhinolaryngol 2021;25(4):e522-e529.

\author{
Address for correspondence Adriana de Oliveira Camargo Gomes, \\ PhD, Department of Speech Therapy, Federal University of \\ Pernambuco, Av. Prof. Artur de Sá, s/n, Cidade Universitária, Recife, \\ Pernambuco, 50670-420, Brazil \\ (e-mail: acamargogomes@gmail.com).
}

\begin{abstract}
Introduction Minor structural alterations of the vocal fold cover are important causes of dysphonia. The variability in the type of alteration and the grade of vocal deviation affects the definition of the conduit and the results of treatment.

Objective To characterize the occurrence, the selected treatments adopted and vocal quality before and after treatment in patients with minor structural alterations of the vocal folds cover.

Methods This was a cross-sectional study based on the records of patients treated by an interdisciplinary team at the laryngology outpatient clinic of a public university hospital from 2010 to 2018. Data collection consisted of access to a database of information on otorhinolaryngological diagnostic hypotheses, intervention and perceptual-auditory vocal assessments before and after the treatment. Data from 102 subjects were analyzed. Association tests were applied between the perceptualauditory vocal results and the different alterations found and between these and the adopted treatments. The results of the degrees of vocal deviation before and after treatment were also compared.

Results The degree of roughness was associated with the sulcus vocalis, and in this

Keywords

- vocal folds

- voice disorders

- speech therapy

- voice quality

- microsurgery alteration the highest occurrence was mild degree of roughness. There was an improvement in the breathiness and general grade of vocal deviation after treatment. Conclusion Cysts were the most frequent structural alteration in the population studied. There was an association between the degree of general deviation and that of roughness in sulcus vocalis cases. The breathiness and the general grade of vocal deviation improved after treatment regardless of the type of treatment and alteration.
\end{abstract}

received

April 24, 2020

accepted

September 24, 2020

published online

December 8, 2020
DOI https://doi.org/ 10.1055/s-0040-1719121. ISSN 1809-9777.

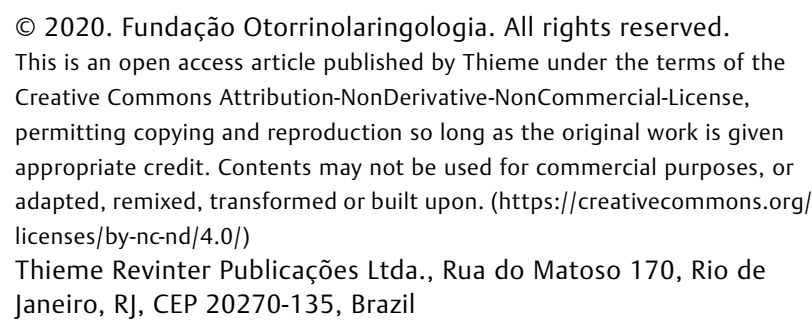




\section{Introduction}

Minor structural alterations of the vocal folds cover (MSAC) consist of undifferentiated and/or differentiated histological changes in the mucosa that covers the vocal muscle. These changes can compromise the vibratory performance of the structure and can lead to dysphonia. Among the differentiated structural alterations to the vocal folds are sulcus vocalis, epidermoid cysts, laryngeal microdiaphragms, mucosal bridges and vasculodysgenesis. ${ }^{1-3}$ Such alterations can present themselves in an isolated or multiple way, in a single vocal fold or both, as well as being associated with undifferentiated structural alterations. ${ }^{1,4-6}$

In general, the clinical impacts, when they exist, are limited to dysphonia, varying according to the type, extent and degree of adherence to the deeper layers of the lamina propria, as well as the combination of the laryngeal problems of a structural nature and their effects on vocal behavior. ${ }^{1,7}$

In the case of the sulcus vocalis, for example, voice disorders range from asymptomatic cases or with slight deviation in the fundamental frequency to a significant degree of hoarseness and breathiness. ${ }^{1,8,9}$ According to the Ford classification, ${ }^{10}$ such variations may be associated with the subdivision of the sulcus vocalis into three different types. In the "physiological" type I variant, the longitudinal depression is restricted to the epithelium and can present asymptomatically. In types II and III, there is involvement of the lamina propria with lesser or greater degree of mucous invagination and the presence of vocal abnormalities. ${ }^{10}$ Type II corresponds to the vergeture and type III to the sulcus vocalis itself, both defined in the classification by Bouchayer et al. ${ }^{11}$

Epidermoid cysts, in turn, when symptomatic, present roughness and severe changes to the fundamental frequency. ${ }^{8}$ In laryngeal microdiaphragms, mucosa bridges and vasculodysgenesis, the consequences for vocal quality vary according to the association with other pathologies. ${ }^{1,12,13}$

Since these characteristics vary between the structural alterations that make up the MSAC, otorhinolaryngological and speech-language evaluations, images and auditory-perceptual observations complement each other and favor the most accurate diagnosis and the definition of the most appropriate intervention. ${ }^{14}$

As for the auditory-perceptual analysis, a numerical scale comprised of six standards: general level of dysphonia $(G)$, roughness (R), soprosity (B), asthenia (A), strain (S), and instability (I), named GRBASI scale is still widely used, as it favors vocal characterization at the time of assessment with measurement of the degree of deviation and helps in defining the most appropriate intervention to be adopted, as well as being useful for monitoring the evolution of the clinical condition. ${ }^{15,16}$

Regardless of the type of treatment, surgical and speech therapies are important alternatives for improving the vocal quality of these patients. Depending on the MSAC subtype and the degree of voice impairment, the recommendation for isolated or combined treatments is observed. With combined intervention (surgery and speech therapy), the choice of one or the other as the primary approach depends on factors such as obtaining satisfactory improvement with conservative treatment. ${ }^{4-6,9,17-20}$

Thus, knowing the vocal quality through auditory-perceptual analysis can allow us to verify not only the parameters that are typically altered but also those that can be improved, favoring the adoption of a more assertive intervention for each subtype of MSAC.

For these reasons, the present study aims to characterize the occurrence, the selected treatments and the vocal quality, before and after treatment, of patients with MSAC of vocal folds and to verify the statistical association between the auditory-perceptual vocal results and the different structural alterations and between the adopted treatments and the structural alterations.

\section{Method}

In the present cross-sectional retrospective study, the studied population consisted of patients referred to the laryngology outpatient clinic of a public university hospital. Patients were evaluated by an interdisciplinary team of otolaryngologists and speech therapists who were part of an extension project developed at the institution, in partnership with the hospital. Patients are submitted to a videolaryngological evaluation, which was used for the diagnosis of morphological alterations.

The inclusion criterion adopted was all patients seen at the clinical meetings of the laryngology outpatient clinic, from May 2010 to April 2018, whose otorhinolaryngological diagnostic hypothesis was MSAC. Thus, all patients in these conditions were included in the calculation of the occurrence of MSAC found. As an exclusion criterion, all patients whose records were incomplete in the database were eliminated from the applied analysis.

The auditory-perceptual analysis was assessed by at least two speech therapists experienced in voice assessment using the GRBASI scale. For this assessment, the patient was asked to emit a sustained vowel in a normal tone and to emit stretches of spontaneous and/or chained speech.

The speech therapists present at the time of the examination established the degree of each parameter by consensus. In a study prior to the present one, the evaluators had participated in a perceptual-auditory judgment calibration training, whose intra- and interjudge agreement was tested using the intraclass correlation coefficient (ICC). This is equivalent to the Kappa statistic for continuous variables. In all cases, the level of agreement was considered as excellent (ICC $\geq 0.75$ ), with the exception of the breathiness parameter, which was considered satisfactory (ICC $=0.66$ ).

Patient identification, medical complaint, diagnostic hypothesis, type of treatment and vocal quality were recorded in the extension project database that served as the basis for the present research. The collection consisted of the selection of records of patients with MSAC registered in the database from May 2010 to April 2018. Of the 882 registered patients, 102 were diagnosed with MSAC and therefore were included in the study and used as the basis for the calculation of the occurrence of MSAC in relation to other 
524 Vocal Quality and Minor Structural Alterations da Silva Brito et al.

pathologies. The present study was approved by the Research Ethics Committee on Human Beings of the Institution, under the ruling number 1.619.520.

To characterize the voice of patients diagnosed with MSAC, the parameters of the GRBASI scale in the pre- and post-treatment evaluation were used. Of the 102 individuals, only 81 had complete records of the GRBASI scale before the application of the treatment (pretreatment evaluation), and 50 records with an indication of the intervention performed, which was therefore the number of patients used to characterize the MSAC according to vocal quality and treatment performed, respectively.
Regarding the records of auditory-perceptual assessment both before and after treatment, 28 subjects had this information recorded in the database and were counted in the comparison of vocal results before and after treatment. There were individuals with more than one subtype of MSAC; therefore, the number of cases considered in the Tables correspond to the number of MSACs found and not to the number of patients in the sample. - Fig. 1 shows a flowchart of these operations.

The statistical association between the auditory-perceptual vocal results and the different structural alterations and between the adopted treatments and the structural alterations was tested. As they are categorical variables, the Pearson chi-

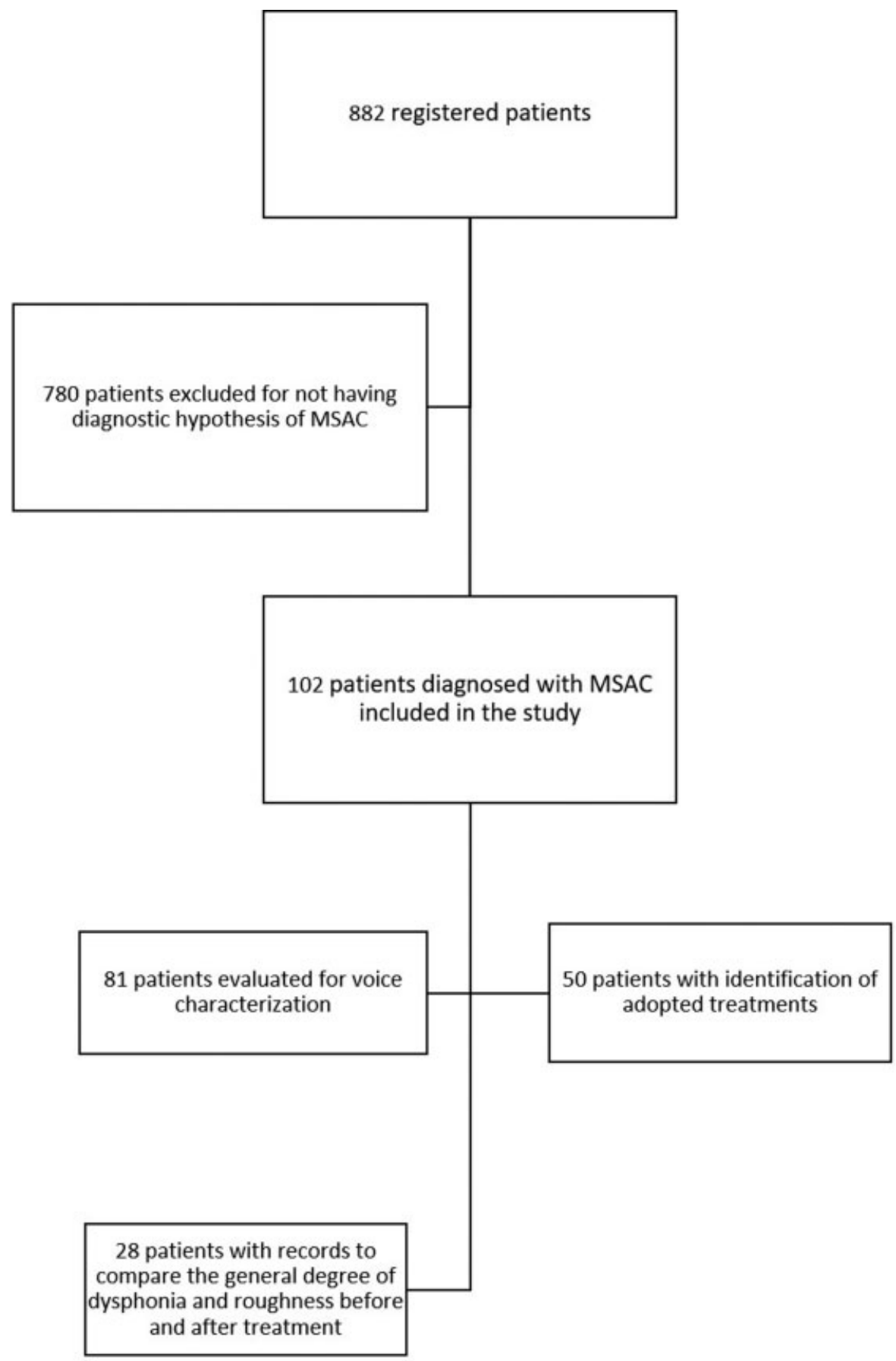

Fig. 1 Data analysis flowchart 
Table 1 Occurrence of the minor structural alterations of the vocal folds cover in 102 subjects

\begin{tabular}{|l|l|l|l|}
\hline \multicolumn{2}{|l|}{ MINOR STRUCTURAL ALTERATIONS } & $\boldsymbol{n}$ & $\%$ \\
\hline Undifferentiated & & 28 & 11.0 \\
\hline Differentiated & 81 & 31.8 \\
\hline & epidermoid cysts & 35 & 13.7 \\
\hline & sulcus vocalis & 25 & 9.8 \\
\hline & vasculodysgenesis & 19 & 7.5 \\
\hline Associated & $\begin{array}{l}\text { laryngeal } \\
\text { microdiaphragm }\end{array}$ & 8 & 3.1 \\
\hline Total & & 59 & 23.1 \\
\hline
\end{tabular}

*corresponding to number of the alterations found in 102 subjects

squared test was used. For the comparison between the results of the degrees of vocal deviations before and after treatment, the Marginal Homogeneity Test was used. In all cases, the level of significance at $5 \%$ was considered. The software used for the analyzes was SPSS Statistics for Windows, version 17.0 (SPSS Inc., Chicago, IL, USA).

\section{Results}

Of the 882 patients seen at the outpatient clinic during the study period, 102 (12\%: 81 female and 21 male) received a diagnosis of MSAC. The average age was $39.2( \pm 13.173)$ years old in the female population, and $34.10( \pm 14.341)$ years old in male subjects. Due to the presence of individuals with more than one subtype of MSAC, the number of cases shown in - Tables 1-3 refers to the number of structural alterations found.

Regarding the subtypes, there was a higher occurrence of determined MSAC than of the undetermined ones, and epidermoid cyst was the most frequently identified structural alteration (-Table 1). No cases of mucosal bridge were found.

The parameters for general grade of vocal deviation $(G)$, roughness (R) and breathiness (B) on the GRBASI scale were those that had the highest scores both in the pre- and posttreatment evaluation, and were the parameters used in the characterization of the voice of the patient in the present study. The parameters asthenia (A), strain (S) and instability (I) were not considered to analysis because their occurrence was insignificant in the sample studied. There was a statistical association between the general grade of vocal deviation and the sulcus vocalis and degree of roughness and the sulcus vocalis $(p<0.05)$. There was also a higher occurrence of mild general grade $(p=0.046)$ and mild roughness $(p=0.020)$ in individuals with a sulcus vocalis. Laryngeal microdiaphragm was the structural alteration that presented the highest percentage of moderate dysphonia in $G$ and $R$ parameters. There was a reduced number of individuals with severe dysphonia (-Table 2).

As for the types of treatment adopted, it is observed that speech therapy was performed at least $50 \%$ of the time in all subtypes of MSAC, even when they were associated with

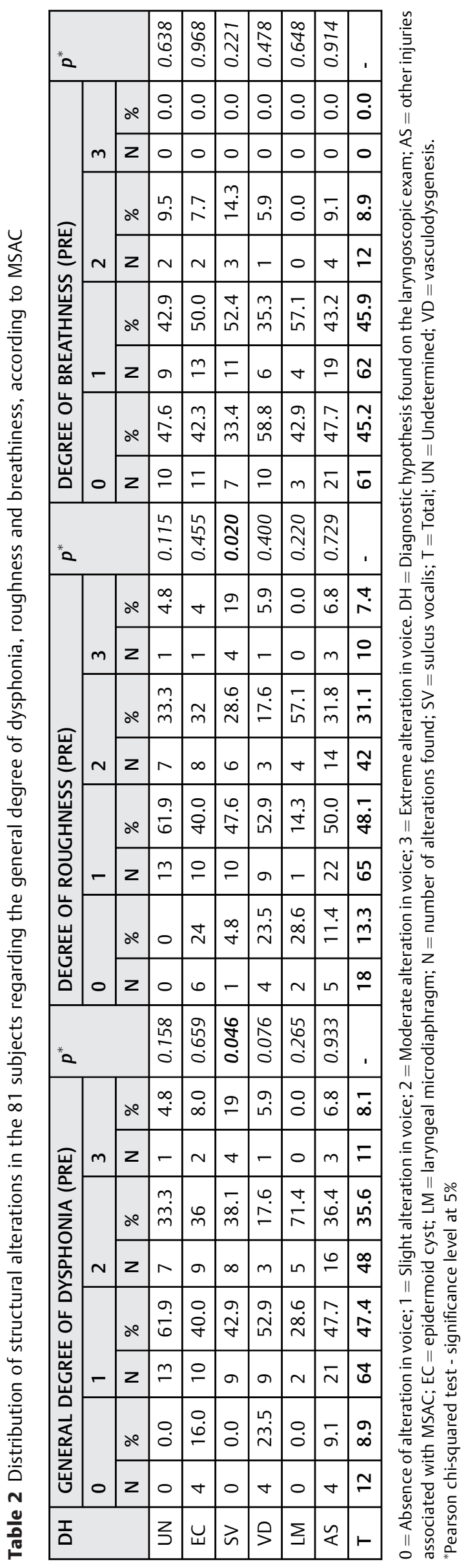


Table 3 Occurrence of the treatments adopted in each subclassification of MSAC in 50 subjects

\begin{tabular}{|c|c|c|c|c|c|c|c|c|c|}
\hline \multirow[t]{3}{*}{ HD } & \multicolumn{9}{|c|}{ TREATMENTS } \\
\hline & \multicolumn{2}{|c|}{ (ST) } & \multicolumn{2}{|l|}{ (S) } & \multicolumn{2}{|c|}{ (MT) } & \multicolumn{2}{|c|}{ (0) } & \multirow[t]{2}{*}{$p$-value } \\
\hline & $\mathrm{N}$ & $\%$ & $\mathrm{~N}$ & $\%$ & $\mathrm{~N}$ & $\%$ & $\mathrm{~N}$ & $\%$ & \\
\hline UN & 11 & 73.0 & 0 & 0.0 & 1 & 7.0 & 3 & 20.0 & 0.083 \\
\hline $\mathrm{EC}$ & 10 & 53.0 & 4 & 21.0 & 4 & 21.0 & 1 & 5.0 & \multirow[t]{4}{*}{0.863} \\
\hline SV & 7 & 50.0 & 2 & 14.0 & 3 & 21.0 & 2 & 14.0 & \\
\hline VD & 7 & 70.0 & 1 & 10.0 & 1 & 10.0 & 1 & 10.0 & \\
\hline LM & 1 & 50.0 & 0 & 0.0 & 1 & 50.0 & 0 & 0.0 & \\
\hline $\mathrm{OL}$ & 17 & 50.0 & 4 & 12.0 & 9 & 26.0 & 4 & 12.0 & 0.246 \\
\hline $\mathrm{T}$ & 53 & 56.4 & 11 & 11.7 & 19 & 20.2 & 11 & 11.7 & - \\
\hline
\end{tabular}

$\mathrm{DH}=$ Diagnosis by the laryngoscopic exam; $\mathrm{EC}=$ Epidermoid cyst; $\mathrm{LM}=$ laryngeal microdiaphragm; $\mathrm{MT}$ = More than one treatment; $\mathrm{N}=\mathrm{number}$ of alterations; $\mathrm{O}=$ Other treatments; $\mathrm{OL}=$ Other lesions associated with MSAC; $\mathrm{S}=$ Surgery; $\mathrm{ST}=$ speech therapy; $\mathrm{SV}=$ sulcus vocalis; $\mathrm{T}=$ Total; $\mathrm{UN}=$ Undetermined minor structural alteration of the vocal fold cover; $\mathrm{VD}=$ Vasculodysgenesis.

*Pearson chi-squared test - significance level at $5 \%$

Table 4 Frequency table of the degree of the parameters in the GRBASI scale according to vocal results before and after treatment in percentages, regardless of the type of intervention applied and the subtype of MSAC presented in 28 subjects.

\begin{tabular}{|c|c|c|c|c|c|c|c|c|c|}
\hline \multirow[t]{2}{*}{ Degree } & \multicolumn{2}{|l|}{ G } & \multirow[t]{2}{*}{ p-value ${ }^{*}$} & \multicolumn{2}{|l|}{$R$} & \multirow[t]{2}{*}{ p-value } & \multicolumn{2}{|l|}{ B } & \multirow[t]{2}{*}{ p-value* } \\
\hline & $\begin{array}{l}\text { Pre } \\
(\%)\end{array}$ & $\begin{array}{l}\text { Post } \\
\text { (\%) }\end{array}$ & & $\begin{array}{l}\text { Pre } \\
(\%)\end{array}$ & $\begin{array}{l}\text { Post } \\
\text { (\%) }\end{array}$ & & $\begin{array}{l}\text { Pre } \\
(\%)\end{array}$ & $\begin{array}{l}\text { Post } \\
\text { (\%) }\end{array}$ & \\
\hline 0 & 3.6 & 32.1 & \multirow[t]{5}{*}{0.024} & 7.1 & 32.1 & \multirow[t]{5}{*}{0.098} & 42.9 & 75.0 & \multirow[t]{5}{*}{0.022} \\
\hline 1 & 57.1 & 39.3 & & 60.7 & 39.3 & & 46.4 & 21.4 & \\
\hline 2 & 28.6 & 25.0 & & 25.0 & 25.0 & & 10.7 & 3.6 & \\
\hline 3 & 10.7 & 3.6 & & 7.1 & 3.6 & & 0.0 & 0.0 & \\
\hline$T$ & 100 & 100 & & 100 & 100 & & 100 & 100 & \\
\hline
\end{tabular}

$\mathrm{B}=$ Degree of breathness; $\mathrm{G}=$ General degree of vocal alteration; post $=$ post-treatment; pre = pretreatment; $\mathrm{R}=$ Degree of roughness; $\mathrm{T}=$ total. ${ }^{*}$ Marginal Homogeneity Test (to compare pre and post results) - significance level at 5\%

injuries of another nature ( - Table 3 ). There was no statistical association between the structural alterations found and the treatment performed.

Regarding the comparison of the general degree $(G)$, roughness (R) and breathiness (B) before and after treatment, a decrease in the general grade of vocal deviation and in the breathiness is observed after the therapy, and the percentage of individuals without changes in the three parameters increased (-Table 4).

\section{Discussion}

Minor structural alterations of the vocal fold cover are one of the causes of dysphonia. However, the diversity of these structural changes and location of the lesions hinder the clinical diagnosis, which sometimes can be obtained only through surgical intervention. ${ }^{2,9}$

In the present study, the occurrence of MSACs $(12 \%)$ in relation to other laryngeal pathologies corroborates the low frequency of these structural changes encountered in the vocal clinic. ${ }^{21,22}$ This can be justified by the hypothesis that these structural alterations do not necessarily cause dysphonia $^{3,23}$ and that vocal cysts have a higher occurrence in relation to the other subtypes of MSAC. ${ }^{21,22,24,25}$
The low occurrence of MSAC can be justified by the fact that the diagnosis was made through videolaryngoscopy, ${ }^{21,26}$ mainly because during the period studied the service area where the exams were performed still did not have stroboscopy equipment, which is considered the best resource to visualize the mucus-wave movement of the vocal folds. ${ }^{27}$ It is possible that if all patients had been submitted to surgical evaluation, the frequency of this diagnosis would increase. This is because the gold standard examination for this evaluation is suspension laryngoscopy microscopy performed in a surgical center $^{3}$-which, for ethical reasons, was only performed in patients refractory to clinical treatment.

As for the perceptual-auditory parameters of the voice, the general grade of vocal deviation $(G)$, roughness $(R)$ was expected given that the most common subtypes (cyst and sulcus vocalis $)^{21,22}$ present a greater deviation in these parameters. ${ }^{9,28,29}$ However, breathiness (B) occurred more in the structural alterations with associated lesions, which can be justified by the possible interference of these lesions in the glottal closure. ${ }^{30-32}$

In this sense, it is observed that the general degree of vocal deviation and roughness in patients with sulcus vocalis is associated with mild dysphonia in most subjects in this group (-Table 2 ). This result can be explained by the 
possibility that our sample was composed of individuals with sulcus vocalis type I, which has less impact on vocal quality when compared with types II and III. ${ }^{9-11,23,28}$ However, as these data are not included in the patient records, this hypothesis cannot be tested.

Regarding the absence of associations with the other subclassifications of MSAC, such as vasculo-dysgenesis and laryngeal microdiaphragm, it is thought that, in these cases, the co-occurrence with other structural alterations was responsible for the differing degrees of voice deviation, since vasculo-dysgenesis alone does not usually cause vocal impact, ${ }^{1}$ and the extension of the laryngeal microdiaphragm determines the greater or lesser impact on vocal quality. ${ }^{17,33}$

In the case of undetermined structural alterations, the failure to establish this correlation can be attributed to the diversity of laryngeal findings included in this category. It is also worth mentioning the possible change in clinical diagnosis of undetermined to specific MSAC after surgical intervention, ${ }^{26}$ which was also not controlled for in the present study.

As for vocal cysts, it is believed that the difficulties of association between the grade of vocal deviation and this injury have occurred due to the variability in adherence of the cysts to the deeper layers of the vocal folds. ${ }^{1}$ In this sense, the resulting vocal quality is more or less rough depending on its location in the vocal fold.

A possible explanation for the presence of an association of general degrees and roughness to the sulcus vocalis is the fact that roughness, in this structural alteration, is related to worse vocal quality than other MSACs, ${ }^{34}$ which can have a greater impact on oral communication and encourage the search for medical care even though the degree of deviation in the voice was mild.

The subjects with laryngeal microdiaphragm had the highest percentage of moderate dysphonia both in the general degree and in the degree of roughness (-Table 2 ). A possible justification for this finding is the frequent association of laryngeal microdiaphragms with other injuries, which occurred in the present study. Since laryngeal microdiaphragms are identified as structural alterations that, in general, do not result in vocal deviation, ${ }^{1}$ it is believed that co-occurrence with different structural changes of the vocal folds was responsible for the moderate degree of vocal deviation in these cases.

Regarding the general impact of dysphonia, it is noted that only 8.1 and $7.4 \%$ of all subjects had, respectively, general degree and degree of roughness classified as extreme, regardless of the subtype of MSAC ( - Table 2), confirming that the percentage of subjects classified with severe dysphonia in the auditory-perceptual analysis is reduced in the most common subtypes of MSAC. ${ }^{9,28,29,35}$

Speech therapy treatment was performed at least $50 \%$ of the time in all subtypes of MSAC ( - Table 3). It is worth mentioning then that the benefits brought by this therapy and the treatment phase in which it is most indicated are controversial. ${ }^{36-38}$ This is because the objective is to improve the voice with a view to its adaptation despite the structural alteration. ${ }^{28,39,40}$ The adoption of later invasive interventions depends on the success obtained with conservative treatment. ${ }^{38}$
In addition, even though surgical intervention is necessary, individuals undergoing speech therapy prior to laryngeal surgery showed subjective improvement in relation to their self-perception of vocal quality and function. ${ }^{41,39}$

On the other hand, the combination of speech therapy and surgery is considered responsible for obtaining better results for the vocal quality of the patient, and postsurgical therapy is important in helping to improve glottic coaptation and vocal fold mucosa vibration. ${ }^{9,37}$

It is also important to point out that the presence of an interdisciplinary team to diagnosis and define the best intervention may have been one of the factors that influenced the considerable percentage of individuals who underwent speech therapy, since the interdisciplinary discussion of the case at the time of examination facilitated this referral. ${ }^{40}$ Therefore, it is suggested that further longitudinal studies be performed to monitor the results with isolated and combined treatments to assess the effectiveness of the applied techniques and the need for other therapeutic indications.

Regarding the need for treatment of laryngeal microdiaphragms, it varies according to the type and extent of this structural alteration. ${ }^{33}$ Speech therapy is generally indicated to reduce the fundamental frequency ${ }^{1}$ with surgical indications being rare. ${ }^{17}$

The higher occurrence of referral for speech therapy in indeterminate MSAC can be justified by the impossibility of verifying the integrity of the mucous-wave movement of the vocal folds without the strobe light (that was not available at the service in this period of the study). ${ }^{26,27}$ In the case of vasculo-dysgenesis, there are often co-occurring structural alterations signaling the presence of other lesions in the vocal folds. ${ }^{1,6,40}$

As for the comparison of the values of the auditoryperceptual analysis before and after the treatments (-Table 4), it is possible that in most subjects there was an improvement in the general grade of vocal deviation. The absence of improvement in the degree of roughness ( $R$ ) may indicate that, in this sample, the gradation of the general grade of vocal deviation $(G)$ decreased due to the reduction in the degree of deviation from other parameters on the GRBASI scale, such as, for example, tension and breathiness. ${ }^{9,28,29,35}$

In addition, it is believed that the reduced number of individuals per pathology available for pre- and post-treatment comparison has also contributed to the lack of evidence of improvement in the degree of roughness of individuals in this sample.

In general, it was possible to identify the improvement in vocal quality after treatment application, regardless of the subtype presented and the treatment performed. The absence of stroboscopy to perform the tests and the reduced number of individuals with records available in the database for comparison before and after treatment are limiting factors in the present study.

The present study contributes to the monitoring of therapeutic results on vocal quality due to minor structural alterations, emphasizing the importance of interdisciplinary 
action and documentation of cases for diagnosis and interventions that favor the effectiveness of the treatment applied.

As in previous researches, ${ }^{40,42,43}$ in the present study the joint occurrence of several subtypes of MSAC was observed, as well as with injuries of other nature, in a single dysphonic patient. Therefore, it was decided to consider the number of changes instead of considering the number of subjects in the analyzes. In such cases, therefore, the analysis of which pathology influences, in isolation, a specific characteristic for dysphonia becomes imprecise, since each lesion presents a range of different possibilities. ${ }^{1}$ This can be considered a limitation of the study and its advantage should be considered in future prospective studies.

\section{Conclusion}

Cysts were the subtype of minor structural alteration in cover that occurred most frequently in the studied population. Speech therapy was the procedure performed in more than half of the cases. There was an association between the degree of general deviation and that of roughness in cases of sulcus vocalis and the general grade of vocal deviation and the degree of breathiness improved after treatment, regardless of the type of intervention and type of MSAC.

\section{Conflict of Interests}

The authors have no conflict of interests to declare.

\section{References}

1 Behlau M, Azevedo R, Pontes P, Brasil O. Difonias funcionais. In: Behlau VozM.. o livro do especialista. Rio de Janeiro: Revinter; 2013:247-294

2 Silva AR, Machado AJ Jr, Crespo AN. Anatomical study of minor alterations in neonate vocal folds. Rev Bras Otorrinolaringol (Engl Ed) 2014;80(04):311-317

3 Moraes BT, De Biase NG. Prevalence of minor larynx structural alterations: influence on the concept of a normal vocal fold. Otolaryngol Head Neck Surg 2019;160(02):295-301

4 Martins RH, Santana MF, Tavares EL. Vocal cysts: clinical, endoscopic, and surgical aspects. J Voice 2011;25(01):107-110

5 Martins RH, Tavares EL, Fabro AT, Martins MG, Dias NH. Mucosal bridge of the vocal fold: difficulties in the diagnosis and treatment. J Voice 2012;26(01):127-131

6 Chuang A, Badía P, Napolitano C. Quistes de cuerda vocal: experiencia en 44 pacientes del centro de voz del departamento de otorrinolaringología de la pontificia universidad católica de chile. Rev Otorrinolaringol Cir Cabeza Cuello 2017;77(03): 239-245

7 Biase N, Pontes P, Vieira VP, Biase S. The glottal closure in diagnostic of minor structural alterations. Rev Bras Otorrinolaringol 2004;70(04):457-462

8 Silva AR. Estudo de alterações anatômicas menores em pregas vocais de neonatos. Dissertação Campinas: Faculdade de Ciências Médicas da Universidade Estadual de Campinas; 2003

9 Miaśkiewicz B, Szkiełkowska A, Piłka A, Skarżyński H. Results of surgical treatment in patients with sulcus vocalis. Otolaryngol Pol 2015;69(06):7-14

10 Ford CN, Inagi K, Khidr A, Bless DM, Gilchrist KW. Sulcus vocalis: a rational analytical approach to diagnosis and management. Ann Otol Rhinol Laryngol 1996;105(03):189-200
11 Bouchayer M, Cornut G. [Sulcus glottidis. Attempt at nosological and etiopathogenic clarification]. Rev Laryngol Otol Rhinol (Bord) 1987;108(Spec No):391-392

12 Benninger MS, Jacobson B. Vocal nodules, microwebs, and surgery. J Voice 1995;9(03):326-331

13 Ruiz DM, Pontes P, Behlau M, Richieri-Costa A. Laryngeal microweb and vocal nodules. Clinical study in a Brazilian population. Folia Phoniatr Logop 2006;58(06):392-399

14 Cielo CA, Ribeiro VV, Bastilha GR, Schilling NO. Quality of life in voice, perceptual-auditory assessment and voice acoustic analysis of teachers with vocal complaints. Audiol Commun Res 2015;20 (02):130-140

15 Martins PC, Couto TE, Gama ACC. Auditory-perceptual evaluation of the degree of vocal deviation: correlation between the Visual Analogue Scale and Numerical Scale. CoDAS 2015;27(03): 279-284

16 Girardi BB, Marchand DLP, Moreira TC, Drummond RL, Cassol M. Relationship between working conditions and voice symptoms among operators of a model call center. Audiol Commun Res 2017;22:e1738.1-7

17 Parkes WJ, Propst EJ. Advances in the diagnosis, management, and treatment of neonates with laryngeal disorders. Semin Fetal Neonatal Med 2016;21(04):270-276

18 Rajasudhakar R. Effect of voice therapy in sulcus vocalis: A single case study. S Afr J Commun Disord 2016;63(01):e1-e5

19 Marta DS. Disfonia na criança. Dissertação Lisboa: Faculdade de Medicina da Universidade de Lisboa; 2017

20 Siqueira DB. Microcirurgia de laringe no tratamento de crianças disfônicas: Quando e por que indicar. Dissertação Botucatu: Faculdade de Medicina da Universidade Estadual Paulista Júlio de Mesquita Filho; 2018

21 Akbulut S, Altintas H, Oguz H. Videolaryngostroboscopy versus microlaryngoscopy for the diagnosis of benign vocal cord lesions: a prospective clinical study. Eur Arch Otorhinolaryngol 2015;272 (01):131-136

22 Martins RH, do Amaral HA, Tavares EL, Martins MG, Gonçalves TM, Dias NH. Voice disorders: etiology and diagnosis. J Voice 2016;30(06):761.e1-761.e9

23 Soares AB, Moares BT, Araújo ANB, de Biase NG, Lucena JA. Laryngeal and vocal characterization of asymptomatic adults with sulcus vocalis. Int Arch Otorhinolaryngol 2019;23(03): e331-e337

24 Rodrigues J, Estevão R, Sousa A, et al. Microlaryngoscopy Findings review. Rev Port Otorrinolaringol Cir Cab Pesc 2016;54 (02):111-117. Doi: $10.34631 /$ sporl.368

25 Saita V, Allegra E, Marino N, Trapasso S, Monea MC. Videolaryngoscopy during conscious sedation in patients not suitable for phonosurgery by microlaryngoscopy: a pilot study. ORL J Otorhinolaryngol Relat Spec 2017;79(04):185-190

26 Neto JAM, Pinna BR, Neto JC, de Sá Pedroso JE. Comparison between telelaryngoscopy and suspension laryngoscopy in the diagnosis of benign vocal fold lesions. Rev Bras Otorrinolaringol (Engl Ed) 2008;74(06):869-875

27 Sulica L. Laryngoscopy, stroboscopy and other tools for the evaluation of voice disorders. Otolaryngol Clin North Am 2013; 46(01):21-30

28 Yılmaz T. Sulcus vocalis: excision, primary suture and medialization laryngoplasty: personal experience with 44 cases. Eur Arch Otorhinolaryngol 2012;269(11):2381-2389

29 Miaśkiewicz B, Szkiełkowska A, Gos E, Panasiewicz A, Włodarczyk E, Skarżyński PH. Pathological sulcus vocalis: treatment approaches and voice outcomes in 36 patients. Eur Arch Otorhinolaryngol 2018;275(11):2763-2771

30 Chen W, Woo P, Murry T. Vocal fold vibration following surgical intervention in three vocal pathologies: a preliminary study. J Voice 2017;31(05):610-614

31 Chen W, Woo P, Murry T. Vocal fold vibratory changes following surgical intervention. J Voice 2016;30(02):224-227 
32 Tsuji DH, Hachiya A, Dajer ME, Ishikawa CC, Takahashi MT, Montagnoli AN. Improvement of vocal pathologies diagnosis using high-speed videolaryngoscopy. Int Arch Otorhinolaryngol 2014;18(03):294-302

33 Cohen SR. Congenital glottic webs in children. A retrospective review of 51 patients. Ann Otol Rhinol Laryngol Suppl 1985;121:2-16

34 Bouchayer M, Cornut G. Microsurgery for benign lesions of the vocal folds. Ear Nose Throat J 1988;67(06):446-449, 452-454, 456-464 passim

35 Schindler A, Mozzanica F, Maruzzi P, Atac M, De Cristofaro V, Ottaviani F. Multidimensional assessment of vocal changes in benign vocal fold lesions after voice therapy. Auris Nasus Larynx 2013;40(03):291-297

36 Ogawa M, Inohara H. Is voice therapy effective for the treatment of dysphonic patients with benign vocal fold lesions? Auris Nasus Larynx 2018;45(04):661-666

37 Azevedo RR, Gomes AOC, Ubrig MT. Atuação fonoaudiológica pré e pós-microcirurgia de laringe. In: Lopes L, Moreti F, Ribeiro LL, Pereira EC. Fundamentos em Atualidades em Voz Clínica. Rio de Janeiro: Revinter; 2019:217-234
38 Soni RS, Dailey SH. Sulcus Vocalis. Otolaryngol Clin North Am 2019;52(04):735-743

39 Tang SS, Thibeault SL. Timing of voice therapy: a primary investigation of voice outcomes for surgical benign vocal fold lesion patients. J Voice 2017;31(01):129.e1-129.e7

40 Sakae FA, Sasaki F, Sennes LU, Tsuji DH, Imamura R. Vocal fold polyps and cover minimum structural alterations: associated injuries? Rev Bras Otorrinolaringol 2004;70(06):739-741

41 Karle WE, Helman SN, Cooper A, Zhang Y, Pitman MJ. Temporalis fascia transplantation for sulcus vocalis and vocal fold scar: long-term outcomes. Ann Otol Rhinol Laryngol 2018;127 (04):223-228

42 Nerurkar NK, Sapre A, Gosavi R. Mucosal bridges (MB): a 9-year retrospective study of their incidence with a third variant proposed. Eur Arch Otorhinolaryngol 2019;276(01):159-165. Doi: 10.1007/s00405-018-5218-7

43 Sünter AV, Kırgezen T, Yiğit Ö, Çakır M. The association of sulcus vocalis and benign vocal cord lesions: intraoperative findings. Eur Arch Otorhinolaryngol 2019;276(11):3165-3171. Doi: 10.1007/ s00405-019-05623-1 